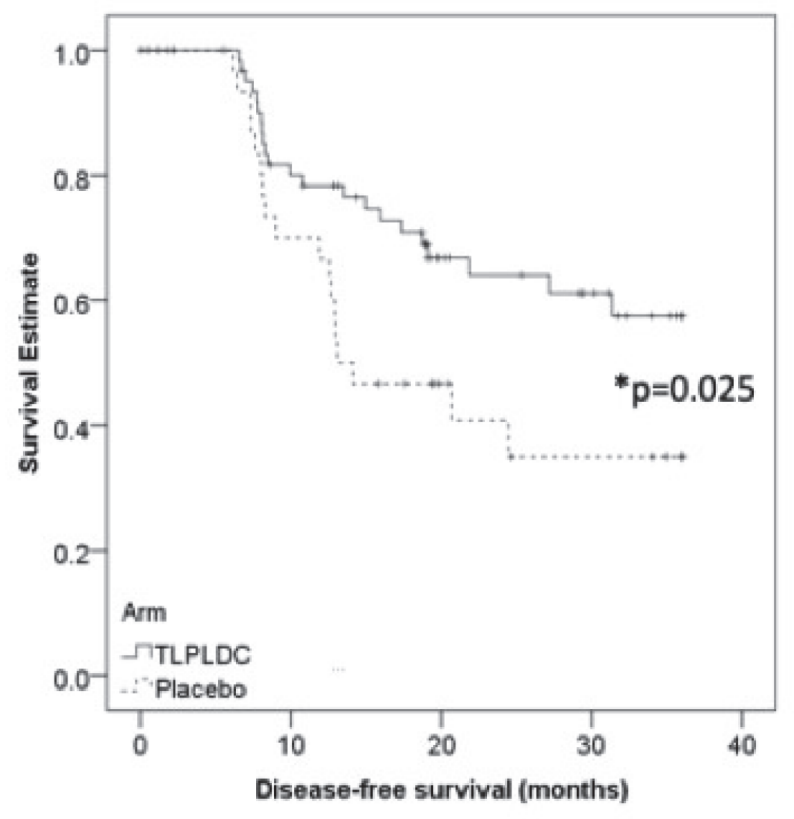

Abstract 300 Figure 136 -month disease free survival for patients receiving TLPLDC vs placebo by PT analysis

Results Overall, 103 patients received TLPLDC and 41 placebo. In PT analysis, 65 patients received TLPLDC and 32 placebo. Total adverse events (AEs), grade $3+$ AEs, and serious AEs (SAEs) were similar in placebo vs TLPLDC groups, with one related SAE per treatment arm. By ITT analysis, 36month OS was $76.2 \%$ for TLPLDC vs $70.3 \%$ for placebo (HR 0.72, $\mathrm{p}=0.437$ ) and 36-month DFS was $35.6 \%$ vs $27.1 \%$ (HR 0.95, p=0.841). By PT analysis, 36-month DFS was improved with TLPLDC $\quad(57.5 \%$ vs $35.0 \%$; HR 0.50 , $\mathrm{p}=0.025$, figure 1$)$. This effect was even more dramatic in resected stage IV patients (36-month DFS: 60.9\% vs 0\%; HR $0.12, \mathrm{p}=0.001$, figure 2).

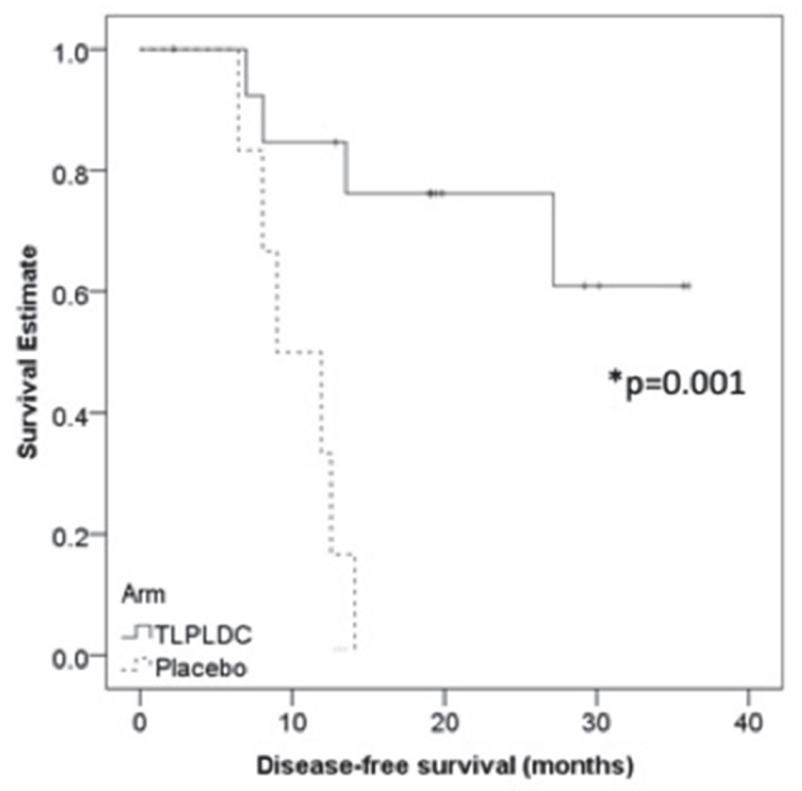

Abstract 300 Figure 2 36-month disease free survival for subset of stage IV melanoma patients receiving TLPLDC vs placebo by PT analysis
Conclusions This phase IIb trial again demonstrates the safety of the TLPLDC vaccine, and an improved 36-month DFS in patients with resected stage III/IV melanoma who complete the primary vaccine series, particularly in the stage IV subgroup. Next, a phase III trial will evaluate the efficacy of TLPLDC vaccine as adjuvant treatment for resected stage IV melanoma, with patients randomized to receive standard of care PD-1 inhibitors + TLPLDC versus PD-1 inhibitors + placebo.

Trial Registration This is a phase IIb clinical trial registered under NCT02301611

Ethics Approval This study was approved by Western IRB, protocol 20141932.

http://dx.doi.org/10.1136/jitc-2020-SITC2020.0300

\section{ASSOCIATION OF RESPONSE WITH SURVIVAL OUTCOMES WITH ATEZOLIZUMAB IN COMBINATION WITH VEMURAFENIB AND COBIMETINIB IN THE PHASE 3 IMSPIRE150 STUDY}

Paolo Ascierto, ${ }^{*}{ }^{2}$ Karl Lewis, ${ }^{3}$ Caroline Robert, ${ }^{4}$ Daniil Stroyakovskiy, ${ }^{5}$ Helen Gogas, ${ }^{6}$ Svetlana Protsenko, ${ }^{7}$ Rodrigo Pereira, ${ }^{8}$ Thomas Eigentler, ${ }^{9}$ Piotr Rutkowski, ${ }^{10}$ Lev Demidov, ${ }^{11}$ Georgy Moiseevich Manikhas, ${ }^{12}$ Haocheng Li, ${ }^{13}$ Qian Zhu, ${ }^{13}$ Edward McKenna, ${ }^{14}$ Virginia MCNally, ${ }^{15}$ Ralf Gutzmer, ${ }^{16}$ Grant MCArthur. ${ }^{1}$ Istituto Nazionale Tumori IRCCS Fondazio, Napoli, Italy; ${ }^{2}$ University of Colorado Comprehensive CC, Aurora, CO, USA; ${ }^{3}$ Gustave Roussy and Université Paris, Villejuif-Paris, France; ${ }^{4}$ Moscow City Oncology Hospital \#62, Istra, Russian Federation; ${ }^{5}$ Laiko General Hospital, Athens, Greece; ${ }^{6} N$. N. Petrov Nat'l Medical Research Ctr of Oncology, St. Petersburg, Russian Federation; ${ }^{7}$ Hospital de Clínicas de Porto Alegre, Porto Alegre, Brazil; ${ }^{8}$ University Hospital Tübingen, Tübingen, Germany; ${ }^{9}$ Maria Sklodowska-Curie National Research, Warsaw, Poland; ${ }^{10}$ N. N. Blokhin Russian Cancer Research, Moscow, Russian Federation; ${ }^{11}$ St. Petersburg Oncology Hospital, St. Petersburg, Russian Federation; ${ }^{12}$ F. Hoffmann-La Roche Ltd, Mississauga, Canada; ${ }^{13}$ Genentech, Inc., South San Francisco, CA, USA; ${ }^{14}$ Roche Products Ltd., Welwyn Garden City, UK; ${ }^{15}$ Haut-Tumour-Zentrum Hannover (HTZH), Hannover, Germany; ${ }^{16}$ Peter MacCallum Cancer Centre, Melbourne, Australia

Background The phase 3 IMspire150 study (NCT02908672) demonstrated improved progression-free survival (PFS) with first-line atezolizumab (A) vs placebo (P) combined with vemurafenib $(\mathrm{V})+$ cobimetinib $(\mathrm{C})$ in patients with $\mathrm{BRAF}^{\mathrm{V} 600}$ mutation-positive advanced melanoma (15.1 vs 10.6 months; hazard ratio $[\mathrm{HR}] \quad 0.78$; 95\% confidence interval [CI] $0.63-$ $0.97 ; \mathrm{P}=0.0249$ ). Objective response has been associated with increased survival with chemotherapy and targeted therapies, but it is unclear whether the association holds for immunotherapy. In this exploratory analysis, we evaluated the impact of response on survival outcomes in patients treated with $\mathrm{A}$ $+\mathrm{V}+\mathrm{C}$ or $\mathrm{P}+\mathrm{V}+\mathrm{C}$ in the IMspire150 study.

Methods 514 patients were randomized $1: 1$ to $\mathrm{A}+\mathrm{V}+\mathrm{C}$ $(n=256)$ or $\mathrm{P}+\mathrm{V}+\mathrm{C}(\mathrm{n}=258)$. Patients received $\mathrm{V}+\mathrm{C}$ in cycle 1; A or $\mathrm{P}$ was added on days $1+15$ from cycle 2 onward. The primary endpoints for this exploratory analysis were PFS and overall survival (OS), estimated using the Kaplan-Meier method. Outcomes were analyzed by investigator-assessed best overall response (BOR) per RECIST v1.1 (complete response [CR] vs partial response [PR] vs stable disease [SD]).

Results Median follow-up was 18.9 mo. In the $\mathrm{A}+\mathrm{V}+\mathrm{C}$ arm, BOR was CR $(n=41), P R(n=129)$, and SD $(n=58)$; in the P $+\mathrm{V}+\mathrm{C}$ arm, BOR was CR $(\mathrm{n}=46), \mathrm{PR}(\mathrm{n}=122)$, and SD $(n=58)$. An imbalance in baseline prognostic factors (eg, lactate dehydrogenase, tumor burden measures) was noted across response categories in both treatment arms, with favorable factors more prevalent in patients with $\mathrm{CR}$ and unfavorable factors more prevalent in patients with $\mathrm{PR} / \mathrm{SD}$. Improvement in 
Abstract 301 Table 1 PFS and OS outcomes with $A+V+C$ vs $P+V$ $+C$ by BOR per RECIST V1.1

\begin{tabular}{|c|c|c|c|}
\hline & $A+V+C$ & $\mathrm{P}+\mathrm{V}+\mathrm{C}$ & $\begin{array}{c}\text { HR for } A+V+C \text { vs } \\
P+V+C \\
(95 \% \mathrm{Cl})\end{array}$ \\
\hline \multicolumn{4}{|c|}{$\begin{array}{l}\text { Median PFS, months } \\
(95 \% \mathrm{Cl})\end{array}$} \\
\hline $\mathrm{CR}$ & NR (23.0-NE) & NR (23.8-NE) & $0.83(0.40-1.72)$ \\
\hline PR & $18.4(15.3-24.0)$ & $12.3(10.4-14.7)$ & $0.64(0.46-0.87)$ \\
\hline$S D$ & $4.8(3.8-5.8)$ & $5.5(4.2-7.4)$ & $0.91(0.61-1.36)$ \\
\hline \multicolumn{4}{|c|}{$\begin{array}{l}\text { 2-year PFS rate, \% } \\
(95 \% \mathrm{Cl})\end{array}$} \\
\hline $\mathrm{CR}$ & $64.6(48.6-80.6)$ & $59.8(43.5-76.0)$ & $\begin{array}{ll}- \\
\end{array}$ \\
\hline PR & $42.1(32.5-51.8)$ & $24.6(16.5-32.8)$ & $\begin{array}{ll}- \\
-\end{array}$ \\
\hline SD & $10.7(1.4-20.0)$ & $\mathrm{NE}$ & - \\
\hline \multicolumn{4}{|c|}{$\begin{array}{l}\text { Median OS, months } \\
(95 \% \mathrm{Cl})\end{array}$} \\
\hline $\mathrm{CR}$ & NR (NE-NE) & NR (NE-NE) & $0.97(0.35-2.67)$ \\
\hline PR & 28.8 (27.4-NE) & 25.6 (22.7-NE) & $0.67(0.44-1.02)$ \\
\hline SD & 14.1 (10.6-NE) & $14.6(10.6-21.2)$ & $0.93(0.58-1.48)$ \\
\hline \multicolumn{4}{|c|}{$\begin{array}{l}\text { 2-year OS rate, \% } \\
(95 \% \mathrm{Cl})\end{array}$} \\
\hline $\mathrm{CR}$ & $82.6(69.4-95.7)$ & $82.8(71.1-94.5)$ & $\begin{array}{ll}- \\
-\end{array}$ \\
\hline PR & $69.1(60.3-77.9)$ & $56.1(46.4-65.8)$ & - \\
\hline$S D$ & $36.6(22.5-50.7)$ & $29.3(15.2-43.5)$ & - \\
\hline
\end{tabular}

PFS and OS was observed with $\mathrm{A}+\mathrm{V}+\mathrm{C}$ vs $\mathrm{P}+\mathrm{V}+\mathrm{C}$ in patients with PR, with 2-year PFS rates of $42.1 \%$ vs $24.6 \%$ and 2-year OS rates of $69.1 \%$ vs $56.1 \%$ with $\mathrm{A}+\mathrm{V}+\mathrm{C}$ vs $\mathrm{P}$ $+\mathrm{V}+\mathrm{C}$ (table 1). In patients with CR, median PFS and OS were not yet reached in either arm, with 2-year PFS rates of $64.6 \%$ vs $59.8 \%$ and 2 -year OS rates of $82.6 \%$ vs $82.8 \%$ with $\mathrm{A}+\mathrm{V}+\mathrm{C}$ vs $\mathrm{P}+\mathrm{V}+\mathrm{C}$. $\mathrm{PFS}$ and $\mathrm{OS}$ outcomes were poor in both treatment arms in patients with SD, with 2-year PFS rates of $10.7 \%$ vs not estimable (NE) and 2-year OS rates of $36.6 \%$ vs $29.3 \%$ with $\mathrm{A}+\mathrm{V}+\mathrm{C}$ vs $\mathrm{P}+\mathrm{V}+\mathrm{C}$.

Conclusions PFS and OS improvement was observed for $\mathrm{A}+\mathrm{V}$ $+\mathrm{C}$ vs $\mathrm{P}+\mathrm{V}+\mathrm{C}$ for patients who achieved PR. CR is associated with improved PFS and $\mathrm{OS}$ with both $\mathrm{A}+\mathrm{V}+\mathrm{C}$ and $\mathrm{P}+\mathrm{V}$ $+\mathrm{C}$. Further follow-up is required to determine the impact of $\mathrm{A}+\mathrm{C}+\mathrm{V}$ vs $\mathrm{P}+\mathrm{C}+\mathrm{V}$ on survival outcomes.

Trial Registration ClinicalTrials. gov, NCT02908672

http://dx.doi.org/10.1136/jitc-2020-SITC2020.0301

\section{A PHASE I TRIAL OF INTRATUMORAL PVSRIPO IN PATIENTS WITH UNRESECTABLE TREATMENT REFRACTORY MELANOMA}

${ }^{1}$ Georgia Beasley*, ${ }^{1}$ Nellie Farrow, ${ }^{1}$ Karenia Landa, ${ }^{1}$ Maria Angelica Seilm, 'Sin-Ho Jung, ${ }^{1}$ Darell Bigner, ${ }^{2}$ Andrea True Kelly, ${ }^{1}$ Smita Nair, ${ }^{1}$ Matthias Gromeier, ${ }^{1}$ April Salama. ${ }^{1}$ Duke University, DURHAM, NC, USA; ${ }^{2}$ Istari Oncology, Durham, NC, USA

Background While PD-1/PD-L1 antagonists have improved the prognosis for many patients with melanoma, the majority fail therapy. PVSRIPO is a novel immunotherapy consisting of a non-neurovirulent rhinovirus:poliovirus chimera that activates innate immunity to facilitate a targeted anti-tumor immune response. Preclinical data show that PVSRIPO plus anti-PD-1 therapy leads to a greater anti-tumor response than either agent alone, warranting clinical investigation.

Methods An open-label phase I trial of intratumoral PVSRIPO in patients with unresectable melanoma (AJCC version 7 stage IIIB, IIIC, or IV) was performed. Eligible patients failed at least prior anti-PD-1 and BRAF/MEK (if BRAF mutant) therapy. The primary objective was to characterize the safety and tolerability of PVSRIPO. 12 patients in 4 cohorts received a total of 1,2 (into 2 different lesions) or 3 (same lesion $3 \mathrm{x}$ or
Abstract 302 Table 1 PVSRIPO anti-tumor response relative to $\mathrm{ICl}$ administration and post-study disease status

\begin{tabular}{|l|c|c|c|c|}
\hline $\begin{array}{c}\text { Time to last } \\
\text { anti-PD-1 } \\
\text { relative to } \\
\text { PVSRIPO }\end{array}$ & ORR per irRC & $\begin{array}{c}\text { Proportion treated } \\
\text { with ICI post- } \\
\text { PVSRIPO }\end{array}$ & $\begin{array}{c}\text { Progression-free post- } \\
\text { PVSRIPO alone or } \\
\text { PVSRIPO followed } \\
\text { by ICI }\end{array}$ & $\begin{array}{c}\text { Median duration of } \\
\text { follow-up } \\
\text { (11 months) }\end{array}$ \\
\hline$\leq 30$ days & $60 \%(3 \text { of } 5)^{1}$ & $80 \%(4$ of 5$)$ & $60 \%(3$ of 5$)$ & 9 months \\
\hline$>30$ days & $14 \%(1$ of 7$)$ & $86 \%(6$ of 7$)$ & $43 \%(3$ of 7$)$ & 14 months \\
\hline \multicolumn{5}{|l|}{2 patients had pathologic complete response in biopsied lesions. } \\
\hline
\end{tabular}

3 different lesions) injections of PVSRIPO monotherapy, 21 days apart.

Results PVSRIPO injections were well tolerated with no SAEs or DLTs reported; all TEAEs were grade (G) 1 or 2 (grade 1 pruritus most common at 58\%), with all but 2 PVSRIPOrelated TEAEs localized to the injected or adjacent lesions ( $\mathrm{n}=1 \mathrm{G} 1$ hot flash, $\mathrm{n}=1 \mathrm{G} 1$ fatigue). Despite the limited number of PVSRIPO treatments relative to the overall lesion burden $(67 \%$ patients $>5$ lesions), 4 of 12 patients $(33 \%)$ achieved an objective response per irRC, including 4/6 (66\%) who received 3 injections (maximum administered). Pathologic complete response (ie, no viable tumor detected in injected and non-injected lesions biopsied) was observed in 2 of 4 (50\%) patients with in-transit disease. PVSRIPO response relative to time since prior anti-PD-1 exposure is summarized in table 1. Following study completion/PVSRIPO therapy, 10/12 patients $(83 \%)$ again received immune checkpoint inhibitor (ICI)-based therapy and 6/12 patients (50\%) remained progression free at the data cutoff.

Conclusions Intratumoral PVSRIPO was well tolerated. When taken together with preclinical data, the anti-tumor responses observed relative to prior or subsequent ICI therapy suggests that PVSRIPO, either alone or in combination with anti-PD-1, may be an effective treatment in anti-PD-1 refractory melanoma. An amendment exploring higher PVSRIPO dose levels is ongoing and a phase 2 study with and without anti-PD-1 in the refractory population is initiating.

Ethics Approval This study (NCT03712358) was approved by WIRB; ID 20181772.

http://dx.doi.org/10.1136/jitc-2020-SITC2020.0302

\section{PHASE II TRIAL OF NEOADJUVANT NIVOLUMAB (NIVO) AND INTRA-TUMORAL (IT) CMP-001 IN HIGH-RISK RESECTABLE MELANOMA (NEO-C-NIVO): FINAL RESULTS}

${ }^{1}$ Diwakar Davar*, ${ }^{2}$ Arivarasan Karunamurthy, ${ }^{2}$ Douglas Hartman, ${ }^{1}$ Richelle DeBlasio, ${ }^{1} \mathrm{Joe}-$ Marc Chauvin, ${ }^{1}$ Quanquan Ding, ${ }^{1}$ Ornella Pagliano, ${ }^{1}$ Amy Rose, ${ }^{1} J o h n$ Kirkwood, ${ }^{1}$ Hassane Zarour. 'Hillman Cancer Center, Pittsburgh, PA, USA; ${ }^{2}$ University of Pittsburgh, Pittsburgh, PA, USA

Background Neoadjuvant PD-1 blockade produces major pathological responses (MPR) in $\sim 30 \%$ of patients (pts) with high-risk resectable melanoma (MEL) with durable relapse-free benefit, and increased circulating activated CD8 + T cells. ${ }^{1}{ }^{2}$ CMP-001 is a type A CpG packaged within a virus-like particle that activates tumor-associated plasmacytoid dendritic cells (pDC) via TLR9 inducing type I interferons and anti-tumor CD8+ T cells. CMP-001/pembrolizumab produces durable anti-tumor responses in PD-1 refractory melanoma. ${ }^{3}$ We previously reported preliminary evidence of efficacy of neoadjuvant IT $\mathrm{CMP} / \mathrm{Nivo}$ in high-risk resectable MEL; and herein present final results on 30 evaluable patients. 


\section{University Library}

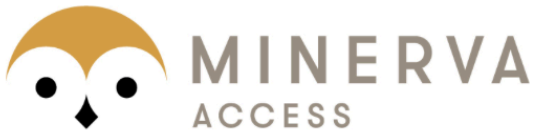

A gateway to Melbourne's research publications

Minerva Access is the Institutional Repository of The University of Melbourne

Author/s:

Ascierto, P;Lewis, K;Robert, C;Stroyakovskiy, D;Gogas, H;Protsenko, S;Pereira, R;Eigentler, T;Rutkowski, P;Demidov, L;Manikhas, GM;Li, H;Zhu, Q;McKenna, E;McNally, V;Gutzmer, R;McArthur, G

Title:

ASSOCIATION OF RESPONSE WITH SURVIVAL OUTCOMES WITH ATEZOLIZUMAB IN COMBINATION WITH VEMURAFENIB AND COBIMETINIB IN THE PHASE 3 IMSPIRE150 STUDY

Date:

2020-11-01

Citation:

Ascierto, P., Lewis, K., Robert, C., Stroyakovskiy, D., Gogas, H., Protsenko, S., Pereira, R., Eigentler, T., Rutkowski, P., Demidov, L., Manikhas, G. M., Li, H., Zhu, Q., McKenna, E., McNally, V., Gutzmer, R. \& McArthur, G. (2020). ASSOCIATION OF RESPONSE WITH SURVIVAL OUTCOMES WITH ATEZOLIZUMAB IN COMBINATION WITH VEMURAFENIB AND COBIMETINIB IN THE PHASE 3 IMSPIRE150 STUDY. [Abstract]. JOURNAL FOR IMMUNOTHERAPY OF CANCER, 8 (Suppl 3), pp.A184-A185. https://doi.org/10.1136/ jitc-2020-SITC2020.0301.

Persistent Link:

http://hdl.handle.net/11343/273967

License:

CC BY-NC-ND 